\title{
PZ-TR: a novel human luciferase reporter cell line for assessment of thyroid receptor transcriptional activity
}

$\overline{\mathrm{P}}$

PALACKÝ

UNIVERSITY

\section{Peter Illes*, Zdenek Dvorak}

Department of Cell Biology and Genetics, Faculty of Science, Palacky University in Olomouc, Slechtitelu 27, 783 71, Olomouc; *peter.illes@upol.cz

ABSTRACT

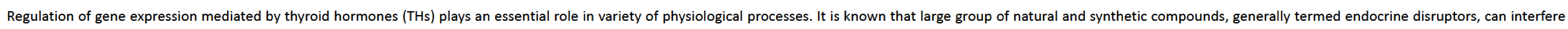

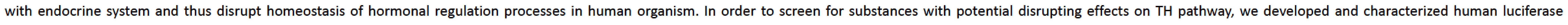

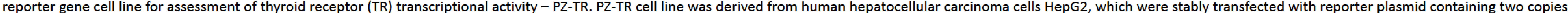

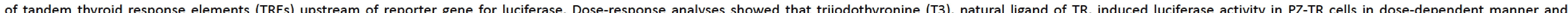

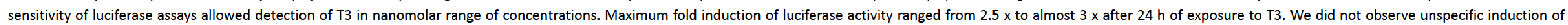

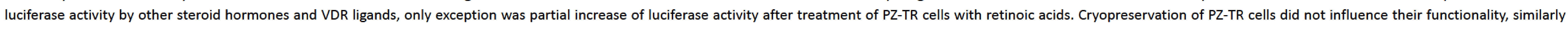

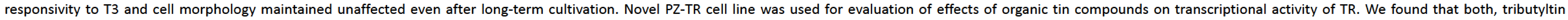

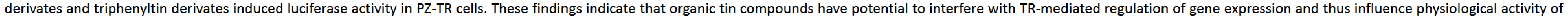
THs.

\section{INTRODUCTION}

Thyroid hormones (THs), triiodothyronine and thyroxine (T3 and T4), regulate gene expression by binding to high-affinity thyroid hormone receptors (TRs) and play a crucial role in growth, development and energy homeostasis. TRs belong to the subfamily of nuclear receptors that recognize specific response elements (TREs) in promoter regions of TH-regulated genes and activate or repress transcription in response to hormone. It is known that large number of exogenous ligands, including natural and synthetic compounds, drugs and environmental pollutants, may disrupt thyroid hormone mode of action and thus affect normal function of endocrine system. Therefore, the development of stable reporter system for assessment of TR transcriptional activity allowing high-throughput screening of effects of various compounds on TR-dependent regulation of gene expression, would be of great benefit.

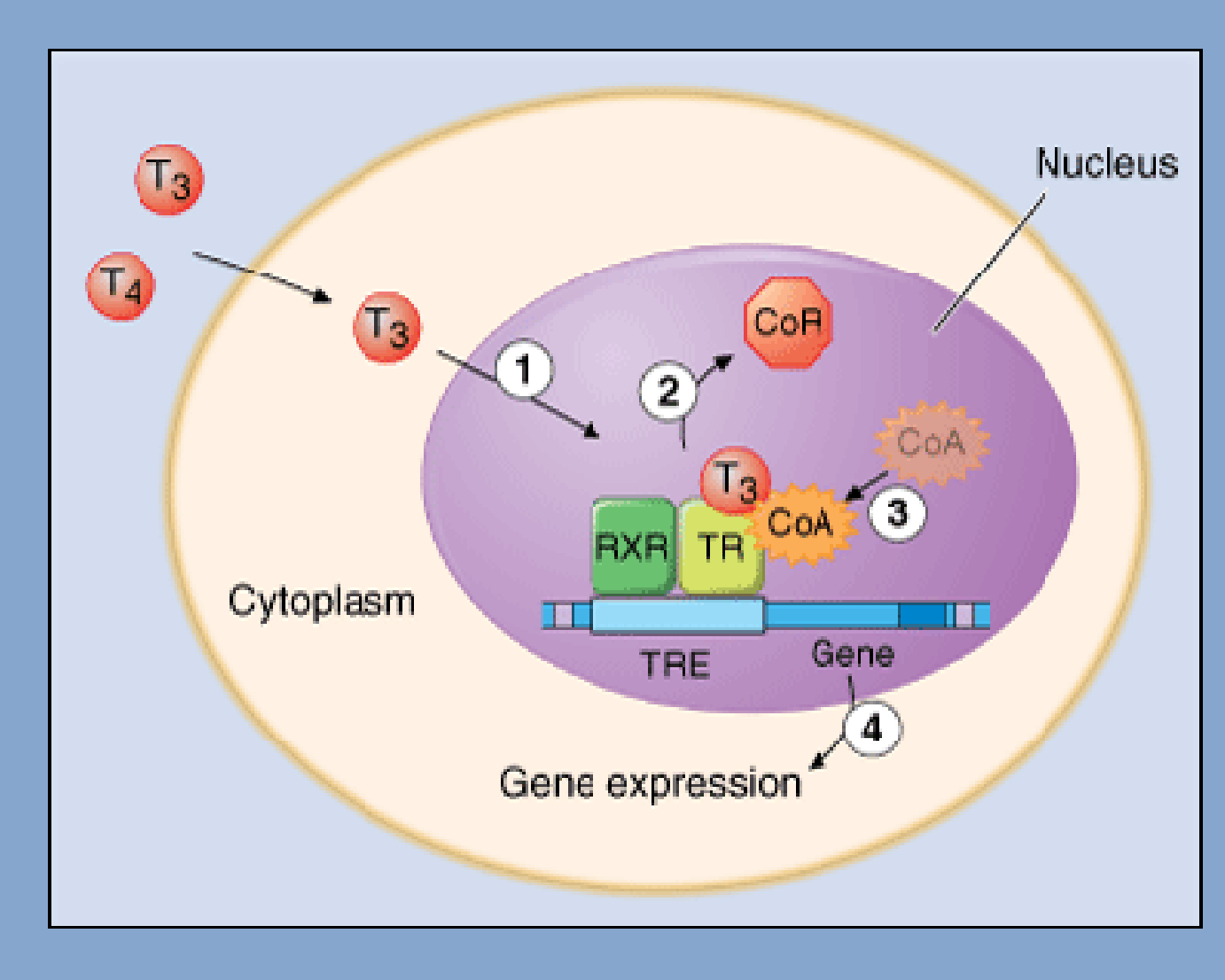

Figure 1. Mechanism of thyroid hormone action. Thyroid hormone receptor (TR) and retinoid $X$ receptor (RXR) form heterodimer that bind specifically to thyroid response element (TRE) in the promoter region of target genes. In the absence of hormone, TR binds co-repressor ( $C O R$ ) proteins that silence gene expression. After the T3 enters the nucleus (1), T3 binding dissociates CoR from TR (2), co-activators (CoA) are recruited to the T3-bound receptor (3) and gene expression is altered (4).

Fauci AS, Kasper DL, Braunwald E, Hauser SL, Longo DL, Jameson JL, Loscalzo J: Harrison's Principles of Internal Medicine, $17^{\text {th }}$ Edition (http://www.accessmedicine.com)

\section{OBJECTIVES}

In our recent work we focused on construction of stably transfected human luciferase reporter cell line for assessment of TR transcriptional activity. The main aim of our experiments was to develop a reliable tool allowing cheap, high-throughput screening for substances with potential disrupting effects on thyroid hormonal pathway.

RESULTS

Novel reporter cell line for assessment of thyroid receptor transcriptional activity PZ-TR was derived from human hepatocellular carcinoma cells HepG2 that were stably transfected with reporter plasmid containing two copies of tandem thyroid response elements (TREs) upstream of reporter gene for luciferase. Doseresponse analyses showed that triiodothyronine (T3) induced luciferase activity in PZ-TR cells in dosedependent manner and sensitivity of luciferase assays allowed detection of $T 3$ in nanomolar range of concentrations. Maximum fold induction of luciferase activity ranged from $2.5 \mathrm{x}$ after $24 \mathrm{~h}$ to almost $3.5 \mathrm{x}$ after $48 \mathrm{~h}$ of exposure to T3. Unspecific induction of luciferase activity by other steroid hormones and VDR ligands was not observed, only exception represented partial increase of luciferase activity after treatment of PZ-TR cells with retinoic acids. Cryopreservation of PZ-TR cells did not influence their functionality, similarly responsivity to T3 and cell morphology maintained unaffected even after long-term cultivation. PZ-TR cell line was used for evaluation of effects of organotin compounds on transcriptional activity of TR. We found that both tested groups, tributyltin derivates and triphenyltin derivates induced luciferase activity in PZ-TR cells. Parallel experiments revealed that organotin compounds are able to enhance effect of $T 3$, especially after treatment with triphenyltin derivates.

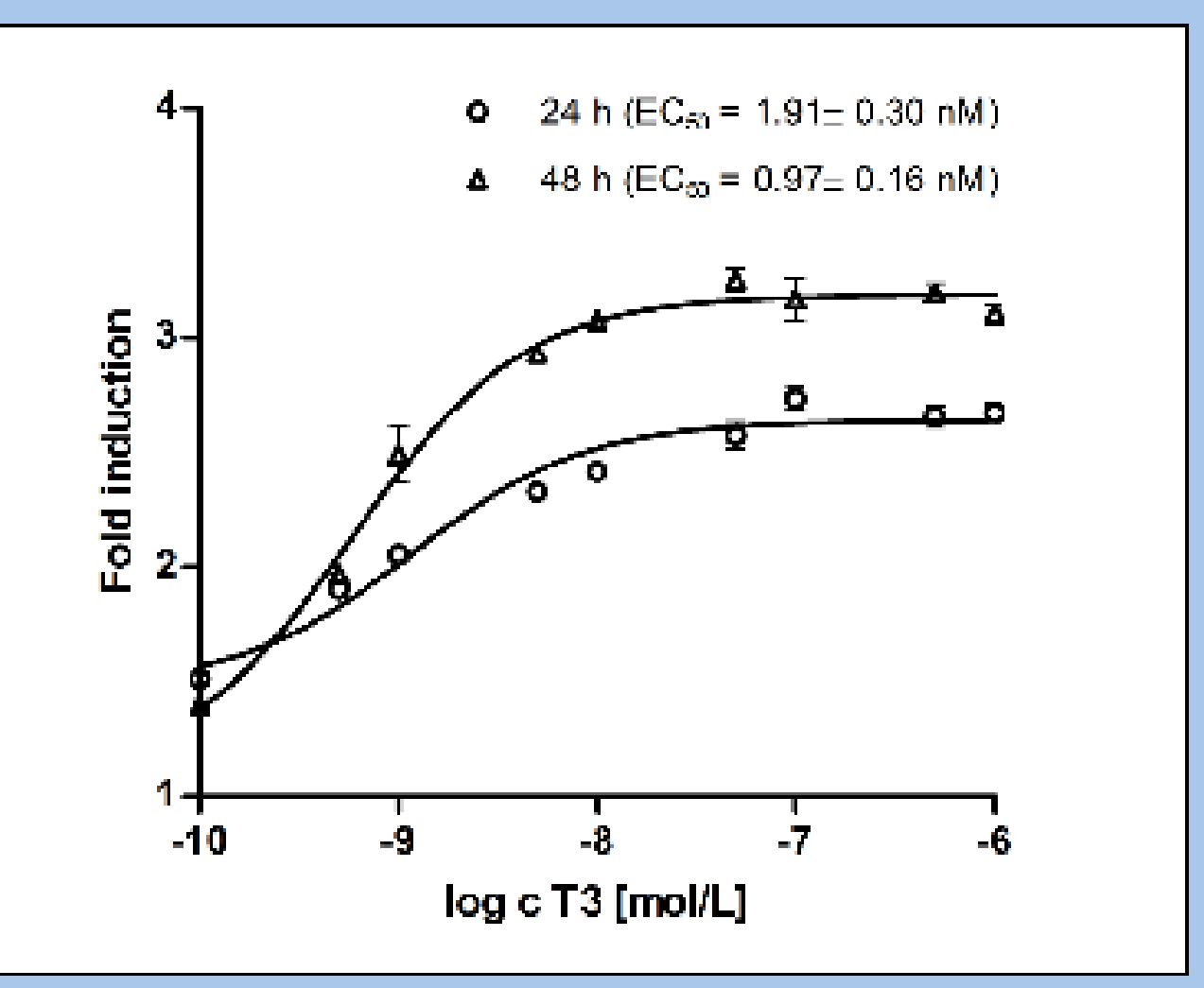

Figure 2. Dose-dependent response of PZ-TR cell line to $T 3$. Cells were treated with range of T3 concentrations $(0.1-1000 \mathrm{nM})$ for 24 and $48 \mathrm{~h}$.

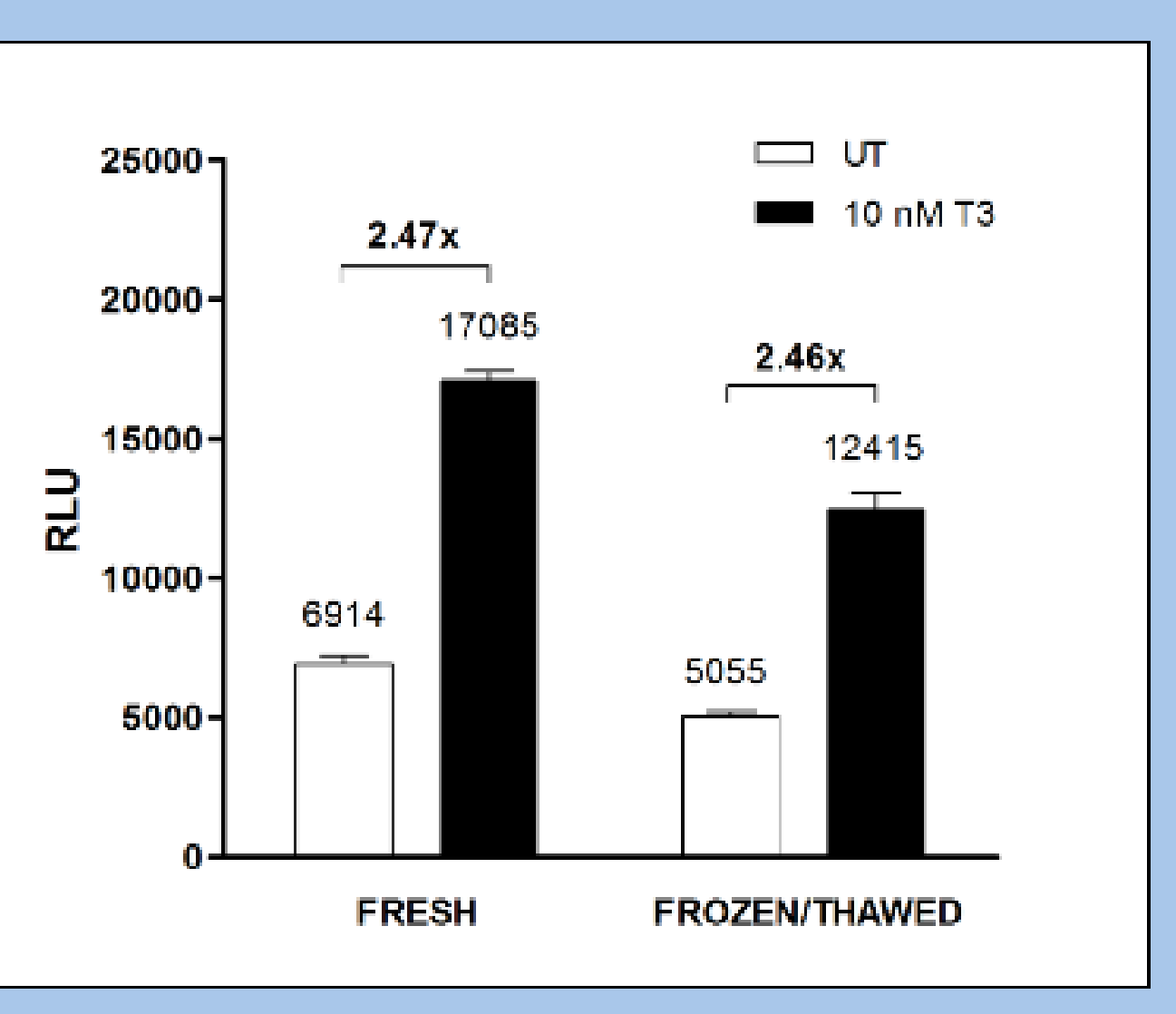

Figure 3. Effect of cryopreservation on functionality of PZ-TR cell line. Experiments were performed on fresh cells and cells after freeze-thaw cycle treated with vehicle (UT; $0.1 \%$ DMSO V/V) and $10 \mathrm{nM}$ T3.

\begin{tabular}{|c|c|c|c|}
\hline Passage number & Days in culture & RLU \pm SD & Fold \\
\hline $\mathbf{0}$ & 4 & $12415 \pm 1109$ & 2,46 \\
\hline $\mathbf{3}$ & 16 & $9205 \pm 68$ & 2,57 \\
\hline $\mathbf{6}$ & 29 & $11344 \pm 954$ & 2,73 \\
\hline $\mathbf{9}$ & 41 & $8944 \pm 520$ & 2,42 \\
\hline $\mathbf{1 2}$ & 54 & $8954 \pm 276$ & 2,45 \\
\hline
\end{tabular}

Table 1. Maintenance of luciferase inducibility by $10 \mathrm{nM}$ T3 after long-term cultivation.

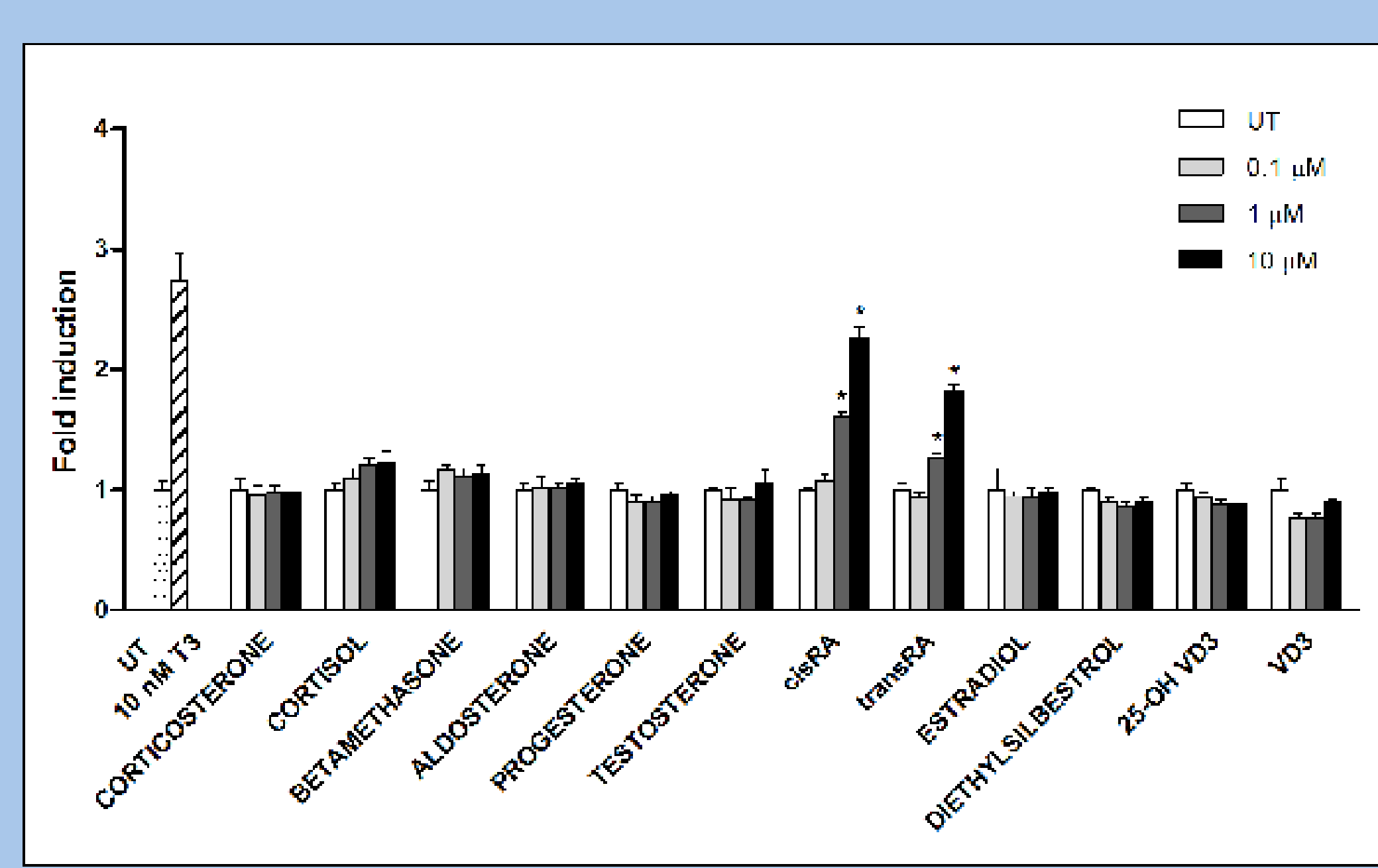

Figure 4. Response of PZ-TR cell line to hormonal treatments. Cells were treated with vehicle (UT; $0.1 \%$ DMSO V/V) and different hormones in concentrations of $0.1 \mathrm{mM}, 1 \mathrm{mM}$ and $10 \mathrm{mM}$ for $24 \mathrm{~h} .{ }^{*}$ - values are significantly different from values of vehicle-treated cells $(p<0.05)$ as determined by Student's t-test.

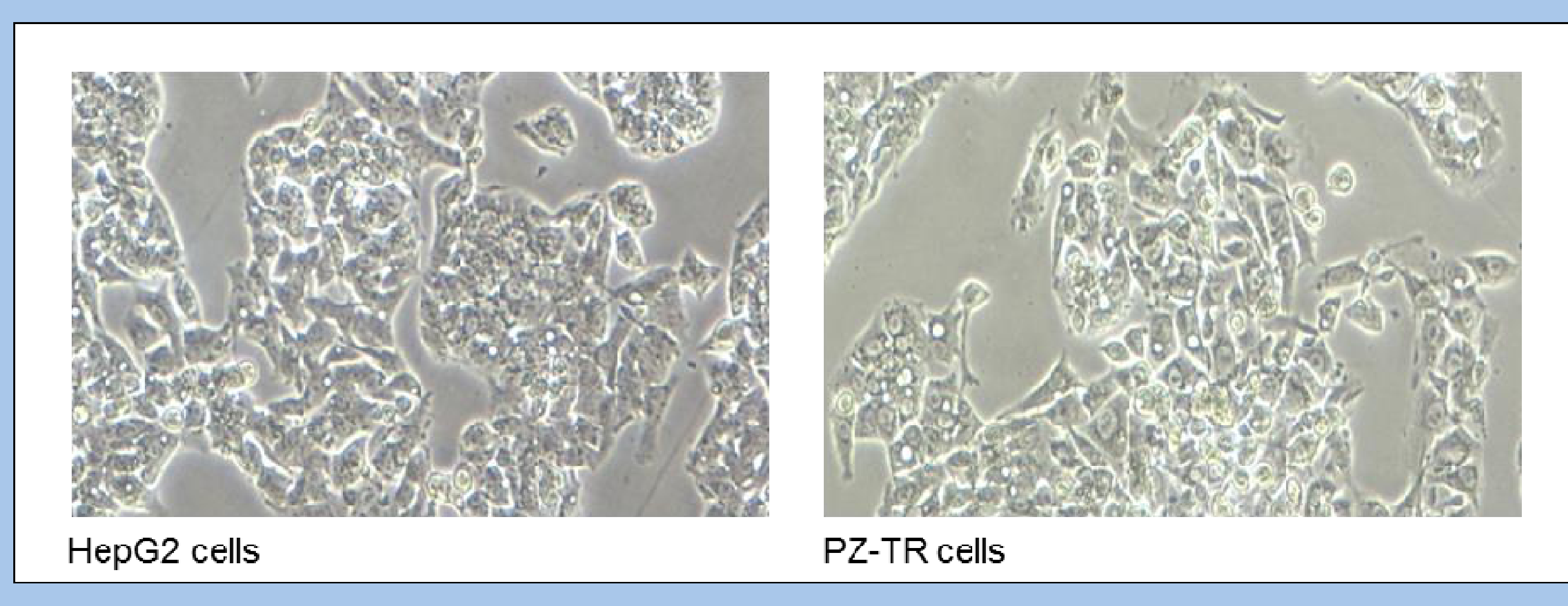

Figure 5. Morphology of HepG2 and PZ-TR cell lines. Phase contrast micrographs of parent HepG2 cells in 8th passage and PZ-TR reporter cells in 10th passage.

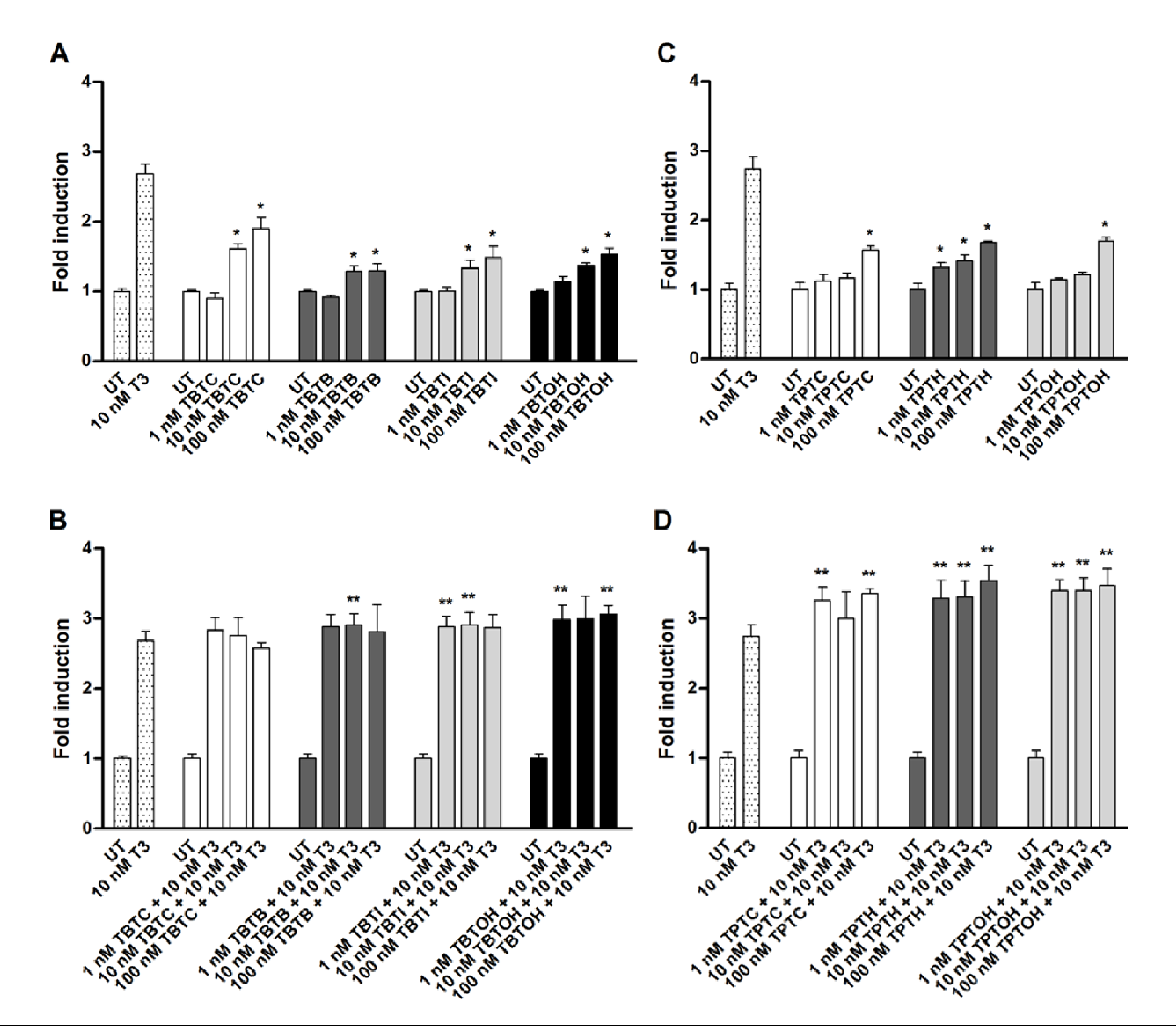

Figure 6. Effect of organotin compounds on transcriptional activity of TRE in PZ-TR reporter cell line. Cells were treated with vehicle (UT; $0.1 \%$ DMSO or/and ethanol V/V), tributyltin derivates (TBTC - tributyltin chloride, TBTB - tributyltin bromide, TBTI - tributyltin iodide, TBTOH - tributyltin hydroxide) (A) and triphenyltin derivates (TPTC - triphenyltin chloride, TPTH - triphenyltin hydride, TPTOH - triphenyltin hydroxide) (C) in concentrations of $1 \mathrm{nM}, 10 \mathrm{nM}$ and 100 $\mathrm{nM}$ alone and in combination with $10 \mathrm{nM}$ T3 (B, D). * - values are significantly different from values of vehicle-treated cells $(p<0.05)$ as determined by Student's t-test. ** - values are significantly different from values of $10 \mathrm{nM}$ T3-treated cells $(p<0.05)$ as determined by Student's t-test.

\section{CONCLUSIONS}

- we developed and characterized novel stably transfected gene reporter cell line PZ-TR - high sensitivity, specificity and through-put

- exclusively human system derived from human HepG2 cells, endogenously expressing both isoforms of TR no need for additional co-transfection with TR expression vector - preservation of stoichiometric ratio between the TR receptor and other transcriptional regulators

organotin compounds have potential to interfere with TR-mediated regulation of gene expression and thus influence physiological activity of thyroid hormone
- PZ-TR cell line - potential tool for pre-clinical testing of drugs, or other natural and synthetic thyroiddisrupting compounds

\section{ACKNOWLEDGEMENT}

This work was supported by the European Social Fund and the Ministry of Education, Youth and Sports of the Czech Republic, Project No. CZ.1.07/2.3.00/30.0004 (POST-UP) and grant from the Czech Scientific Agency GACR 303/12/G163. 